
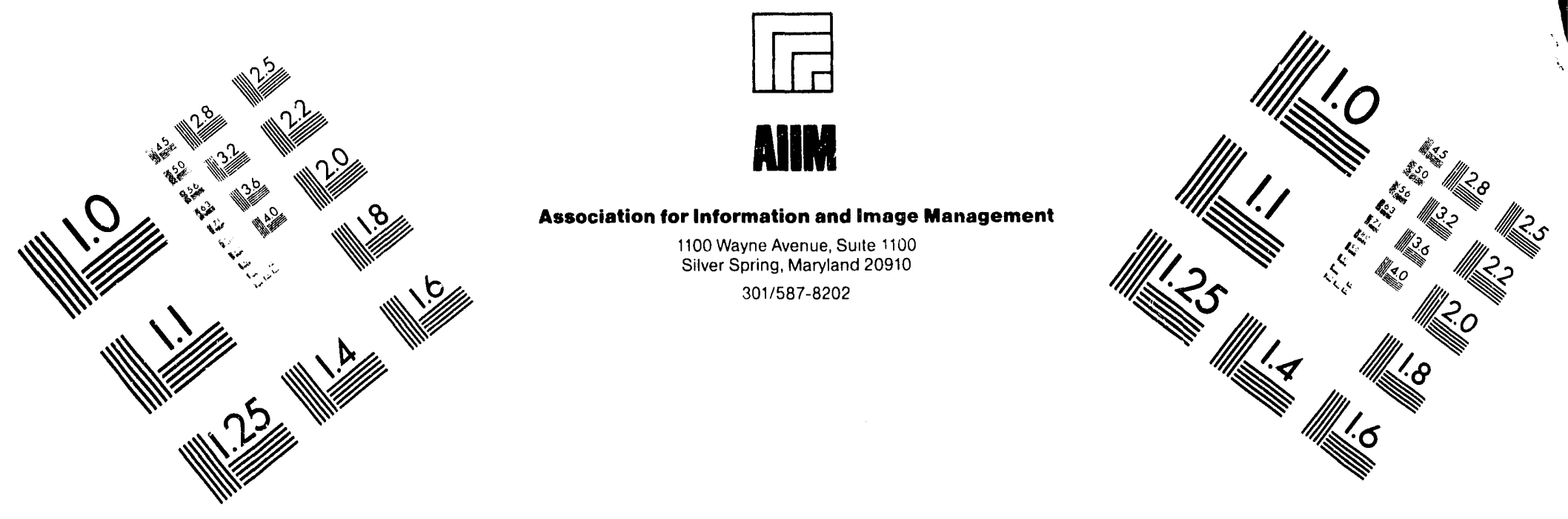

\title{
Centimeter
}

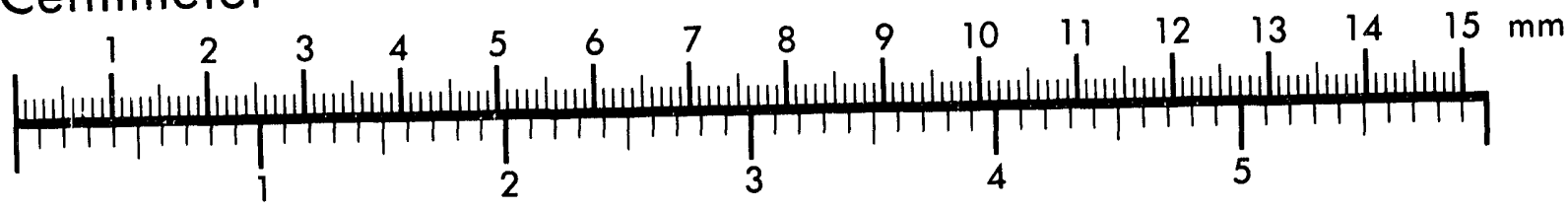
Inches
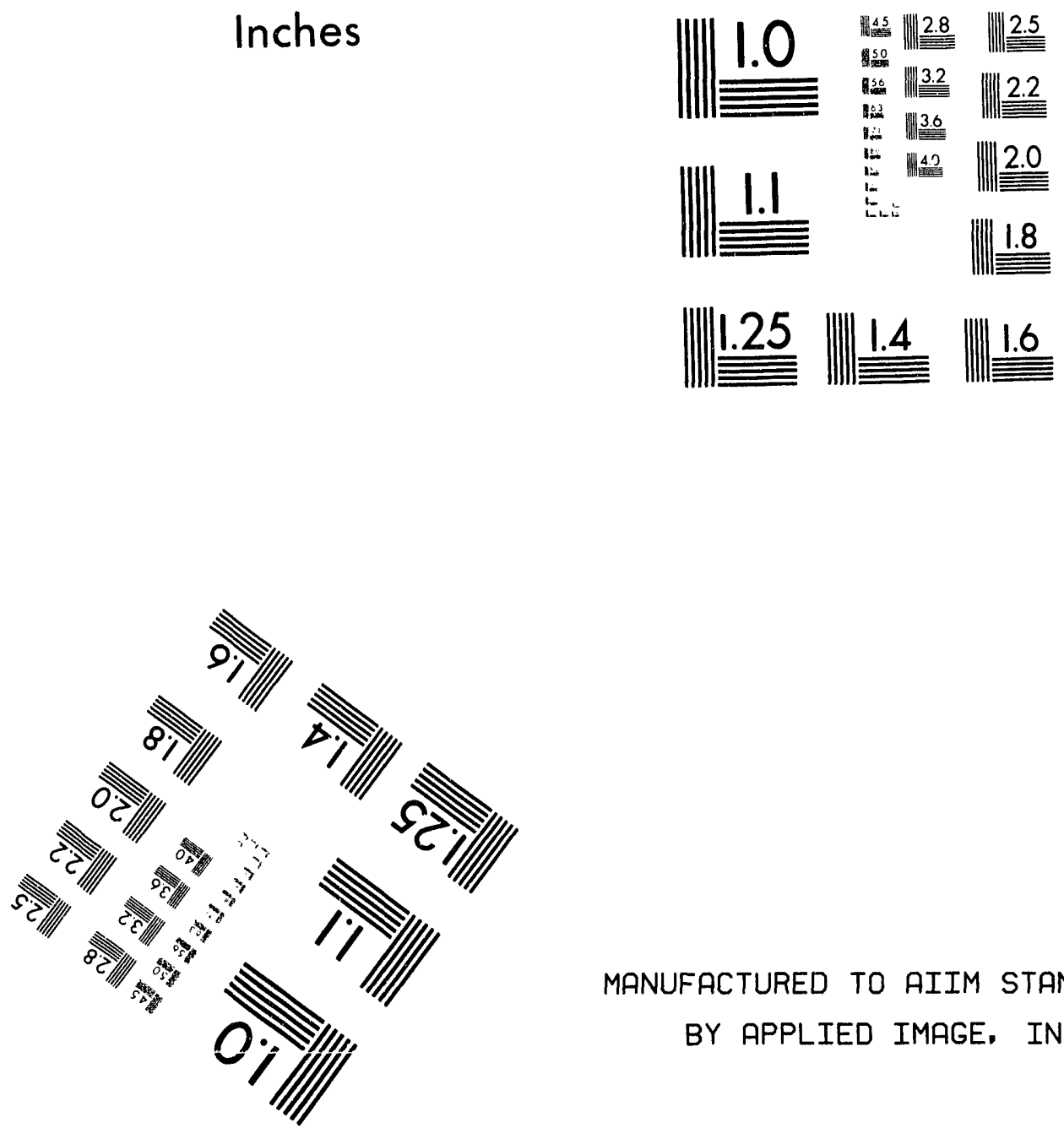

MANUFACTURED TO AIIM STANDARDS

BY APPLIED IMAGE, INC.

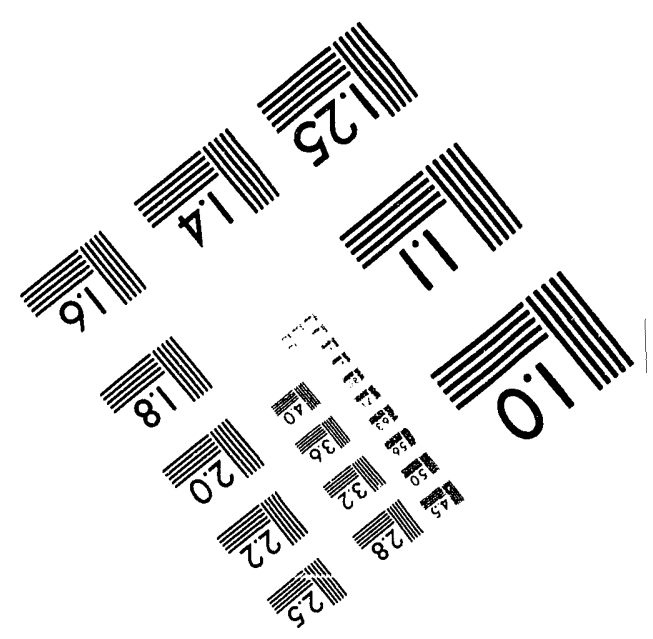



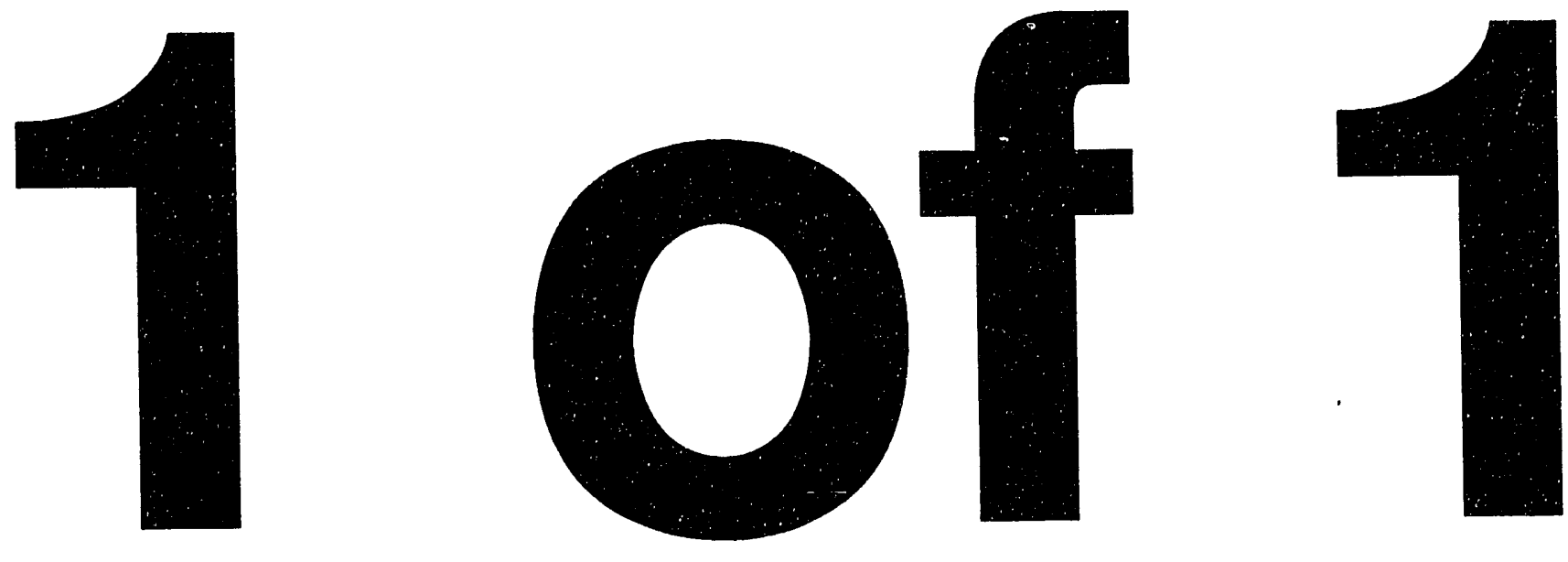


\title{
Test of Fermilab Built, Post-ASST, 50-mm-Aperture, Full Length SSC Dipole Magnets*
}

\author{
J. Kuzminski, et al. \\ Superconducting Super Collider Laboratory ${ }^{\dagger}$ \\ 2550 Beckleymeade Ave. \\ Dallas, TX 75237
}

May 1993

"Presented at the Fifth Annual International Symposium on the Super Collider, May 6-8, 1993 San Francisco, CA.

†Operated by the Universities Research Association, Inc., for the U.S. Department of Energy under Contract No. DE-AC35-89ER40486. 
TEST OF FERMILAB BUILT, POST-ASST, 50-MM-APERTURE, FULL LENGTH SSC DIPOLE MAGNETS

\author{
J. Kuzminski ${ }^{1}$, A. Akhmetov ${ }^{1}$, R. Bossert ${ }^{2}$, T. O. Bush ${ }^{1}$, D. W. Capone II ${ }^{1}$, \\ J. Carson ${ }^{2}$, R. Coombes ${ }^{1}$, S. W. Delchamps ${ }^{2}$, A. Devred ${ }^{1}$, J. DiMarco ${ }^{1}$, \\ C. Goodzeit ${ }^{1}$, S. Gourlay ${ }^{2}$, C. Haddock ${ }^{1}$, R. Hanft ${ }^{2}$, W. Koska ${ }^{2}$, \\ M. Kuchnir ${ }^{2}$, M. J. Lamm², P. Mantsch ${ }^{2}$, J. Marks' ${ }^{1}$, P. O. Mazur ${ }^{2}$, \\ W. Nah ${ }^{1,3}$, T. Ogitsu 1,4 , D. Orris ${ }^{2}$, J. Ozelis ${ }^{2}$, T. Peterson ${ }^{2}$, E. G. Pewitt ${ }^{2}$, \\ P. Sanger ${ }^{1}$, R. Schermer ${ }^{1}$, R. Stiening ${ }^{1}$, J. Strait ${ }^{2}$, J. C. Tompkins ${ }^{1}$, \\ J. Turner ${ }^{1}$, M. Wake ${ }^{1,4}$, J. Zbasnik ${ }^{1}$, Y. Zhao $^{1}$, and H. Zheng ${ }^{1}$ \\ ${ }^{1}$ SSC Laboratory, ${ }^{*} 2550$ Beckleymeade Ave., Dallas, TX 75237 \\ 2 Fermilab, Batavia, IL 60510 \\ ${ }^{3}$ Korea Electrotechnology Research Institute, Changwon, \\ Kyongnam, 641-120, Korea \\ ${ }^{4}$ KEK, National Laboratory for High Energy Physics, \\ Tsukuba, Ibaraki 305, Japan.
}

\title{
INTRODUCTION
}

During 1992 at Fermilab, a series of nine 50-mm-aperture, 15-m-long, SSC superconducting dipole magnets, designed jointly by Fermilab, Brookhaven National Laboratory, and the SSC Laboratory, have been built and successfully cold tested. Seven of these dipole magnets, designated for the Accelerator System String Test (ASST) carried out at SSCL in Dallas, were assembled at Fermilab by General Dynamics personnel, and have achieved the nominal operating current level without significant training ${ }^{1,2}$. In addition, a series of four $R \& D$ magnets (DCA320 323) were manufactured at Fermilab to test an alternative insulation schemes. In this paper we present the quench performance of these four R\&D magnets, which were cold tested at the Fermilab Magnet Test Facility at nominal temperatures of $4.35 \mathrm{~K}, 3.85 \mathrm{~K}$, and $3.50 \mathrm{~K}$. An extended characterization test was performed on one of these magnets (DCA322). During this test the magnet was successfully cooled down to superfluid He temperature $(1.8 \mathrm{~K})$ and reached a field $\mathrm{B} \geq 9.5 \mathrm{~T}$.

\section{MAGNET CONSTRUCTION}

The design of the full-length, 50-mm-aperture SSC dipole magnets has been previously described ${ }^{3,4}$. Here we note only the main features. The magnetic field is generated by a two layer, $\cos (q)$ type coil clamped by stainless steel collars. The collars serve to position the conductor as specified by the magnetic design and to restrain conductor motion under excitation. The upper and lower collars are locked together by tapered keys and left-right pairs of collars are spot welded to provide greater horizontal stiffness. In the Fermilab design, a vertically split yoke is employed to

* Operated by the Universities Research Association, Inc., for the U. S. Department of Energy under Contract No. DE-AC35-89ER40486. 
provide mechanical support to the collars near the horizontal mid-plane and thus to limit deflections under Lorentz force. The $4.95 \mathrm{~mm}$ thick, $340 \mathrm{~mm}$ O.D. stainless steel shell, made from two halfcylinders welded at the vertical parting plane of the yoke, serves as a helium containment vessel and as a structure clamping together the two halves of the vertically split yoke. To provide axial restraint under excitation, a 38-mm thick end plate is welded to each end of the cold mass shell and the collared coil is preloaded axially against these plates by means of four set screws at each end.

The inner coil of each magnet is instrumented with 53 voltage taps located in the six turns nearest the poles. These voltage taps allow for a quench origin determination with a resolution of a few $\mathrm{cm}$ for quenches occurring in the instrumented turns.

All magnets are equipped with two collar packs instrumented with beam-type strain gauge transducers for azimuthal coil stress measurements. 5 These packs are located at positions corresponding to the minimum and maximum of inner coil size. In addition, each magnet has one assembly of load cells, ${ }^{5}$ mounted on the non-lead end of the magnet, to measure the forces between the coil and the end plate during excitation, and gauges on the cold mass shell.

Table 1 presents the details of insulations and adhesives employed in various magnets. There are 5 mil shims in the outer coils of magnet DCA320-321 to account for change in the insulation thickness. Note that both sides of the insulation had adhesive coating in DCA322-323 to increase resistance to conductor motion. ${ }^{6}$

Table 1. Cable insulation employed in magnets DCA320-323.

\begin{tabular}{|c|c|c|}
\hline MAGNET & INSULATION & ADHESIVE \\
\hline DCA320 & $\begin{array}{c}\text { DuPont Kapton } \\
\text { 2H+2LT }\end{array}$ & $\begin{array}{c}\text { 3M 2290 epoxy } \\
\text { one side }\end{array}$ \\
\hline DCA321 & $\begin{array}{c}\text { DuPont Kapton } \\
\text { 2H+2LT }\end{array}$ & $\begin{array}{c}3 \mathrm{M} 2290 \text { epoxy } \\
\text { one side }\end{array}$ \\
\hline DCA322 & Allied Signal Apical & $\begin{array}{c}\text { Allied Signal Cryorad } \\
\text { both sides }\end{array}$ \\
\hline DCA323 & Allied Signal Apical & $\begin{array}{c}\text { Allied Signal Cryorad } \\
\text { both sides }\end{array}$ \\
\hline
\end{tabular}

\section{EXPERIMENTAL PROCEDURE}

The magnet cold testing was carried out at nominal temperatures of $4.35 \mathrm{~K}, 3.85 \mathrm{~K}$ and $3.50 \mathrm{~K}$. The mass flow of supercritical helium at $4 \mathrm{~atm}$ was $\sim 50 \mathrm{~g} / \mathrm{s}$.

The generic test sequence was essentially the same used during testing of ASST magnets, with cool down without a restriction on the temperature difference between the helium inlet and outlet ends of the magnet, and includes two test cycles, separated by warm-up to room temperature. Both testing cycles started at $T=4.35 \mathrm{~K}$ with a strain gauge run to quench with subsequent ramps followed to establish a quench current plateau. During the second testing cycle, after re-establishing a quench plateau at $4.35 \mathrm{~K}$, additional tests at $3.85 \mathrm{~K}$ and $3.50 \mathrm{~K}$ were performed to determine quench performance at these temperatures. Strain gauge ramps to currents $100 \mathrm{~A}$ below blateau were taken at each test temperature.

\section{TEST RESULTS}

Figure 1(a) shows the spontaneous quench performance of the four magnets tested, ordered in the sequence they were tested. All quenches displayed in this plot occurred at a ramp rate $\leq 4 \mathrm{~A} / \mathrm{s}$. The horizontal dashed line shows the design SSC operating current of 6,600 A (corresponding to 6.7 T). The overall quench performance of these magnets is slightly below that obtained in the DCA311-319 series. Among the four, DCA322 showed the poorest quench performance, reaching operating current after the second quench and plateau only on the fifth. As in the ASST series of magnets, no training was observed during the second Testing Cycle (TC).

Figure 1(b) shows quench performance of the magnets at low temperatures. Magnets DCA320 and 321 show little or no training and reach the short-sample limit at $3.85 \mathrm{~K}$ and $3.50 \mathrm{~K}$. There is a one training quench at $3.85 \mathrm{~K}$ in DCA322, and DCA323 exhibits substantial training at all tested temperatures with several quenches originating in the upper outer coil. 


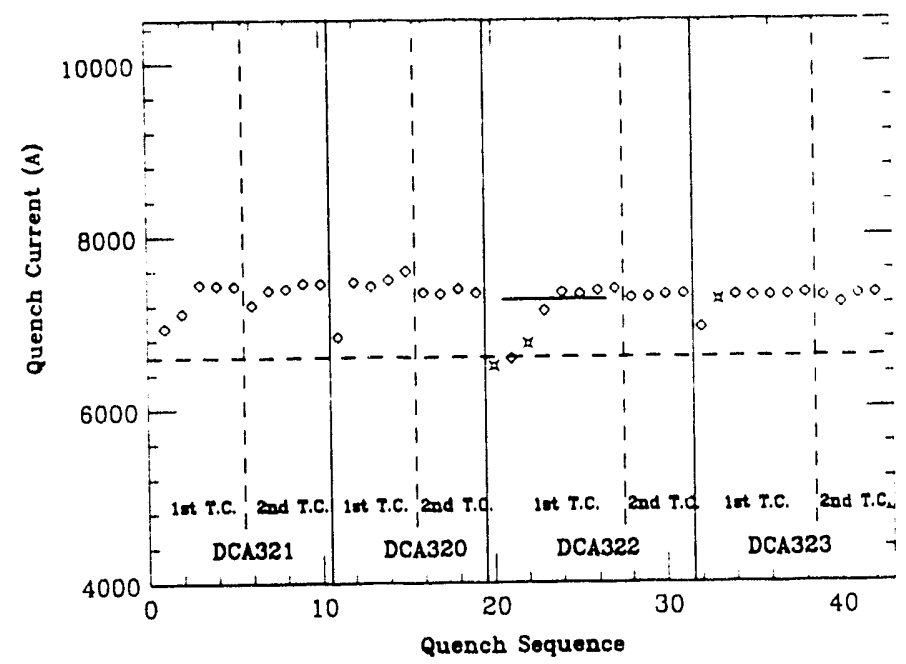

(a)

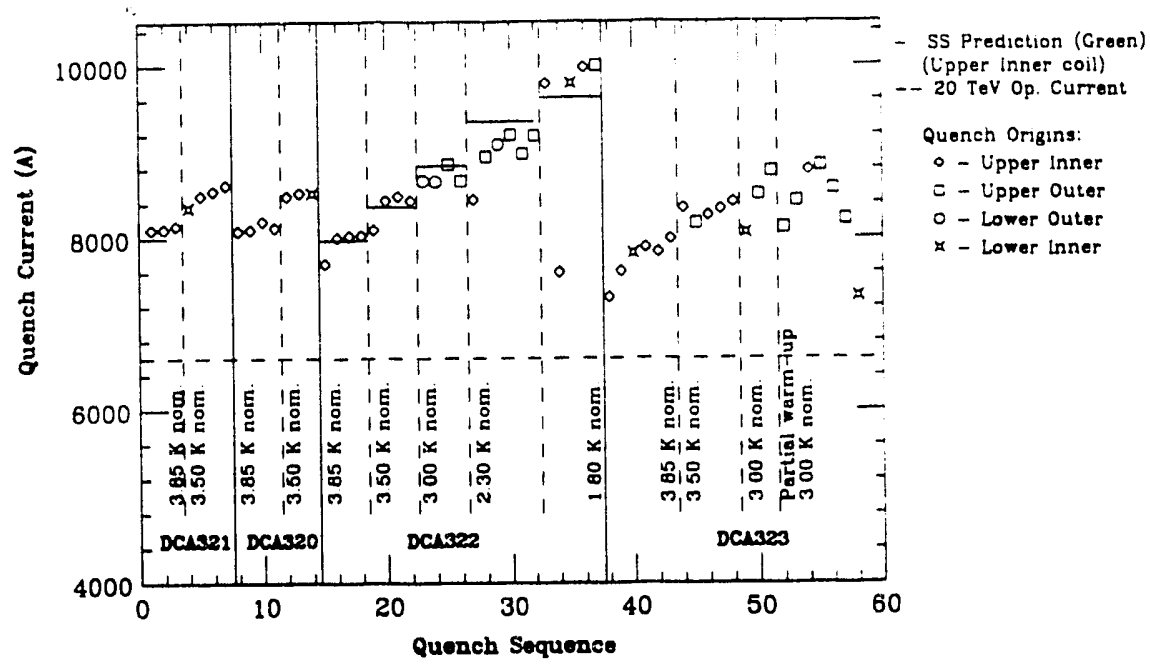

(b)

Figure 1. Spontaneous quench performance at $4.35 \mathrm{~K}$ (a) on the first and second cooldown and at lower temperature (b) during the second cooldown.

An extended characterization test was performed on magnet DCA322. It consisted of coolingdown the magnet to $3.0 \mathrm{~K}, 2.3 \mathrm{~K}$ and then to the super fluid He temperature of $1.80 \mathrm{~K}$. At each step a strain gauge run to quench was performed to check for possible coil unloading during the magnet excitation. Figure 2 shows an example of the azimuthal inner coil stress (a) and end forces (b) as a function of $\mathrm{I}^{2}$. The average stress loss between 0 and $6,500 \mathrm{~A}$ is about $20 \mathrm{MPa}$. The stress is linear with $\mathrm{I}^{2}$, (i.e. with force during excitation) and the prestress is still positive even at the highest current at which strain gauge data were taken $(8,894 \mathrm{~A}$ or $8.8 \mathrm{~T}$.) At this field the magnetic forces are almost twice as large as at the SSC operating field. In all the $50 \mathrm{~mm}$ magnets tested to date, there is no indication of coil unloading. After careful evaluation of strain gauges data, an attempt was made: to establish a quench plateau at each temperature. Figure 1(b) illustrates magnet DCA322 quencki performance; at $1.8 \mathrm{~K}$ the magnet reached a limit of $10,000 \mathrm{~A}(\mathrm{~B} \geq 9.5 \mathrm{~T})$ after several training quenches at $2.3 \mathrm{~K}$.

\section{SUMMARY AND CONCLUSIONS}

Four 50-mm-aperture, full-length SSC R\&D magnets, in addition to nine ASST magnet prototypes, have been built at Fermilab, following the baseline design but with a different cable insulation scheme. These magnets showed more training quenches then previously tested ASST magnets. However, a conclusive correlation between insulation material used and the spontaneous quench performance could not be established. One of these magnets (DCA322) was tested at $1.8 \mathrm{~K}$ and reached a quench plateau at nearly $10,000 \mathrm{~A}(\mathrm{~B} \geq 9.5 \mathrm{~T})$. This extended characterization test confirmed a confidence in the mechanical design of 50-mm aperture magnet prototype. 


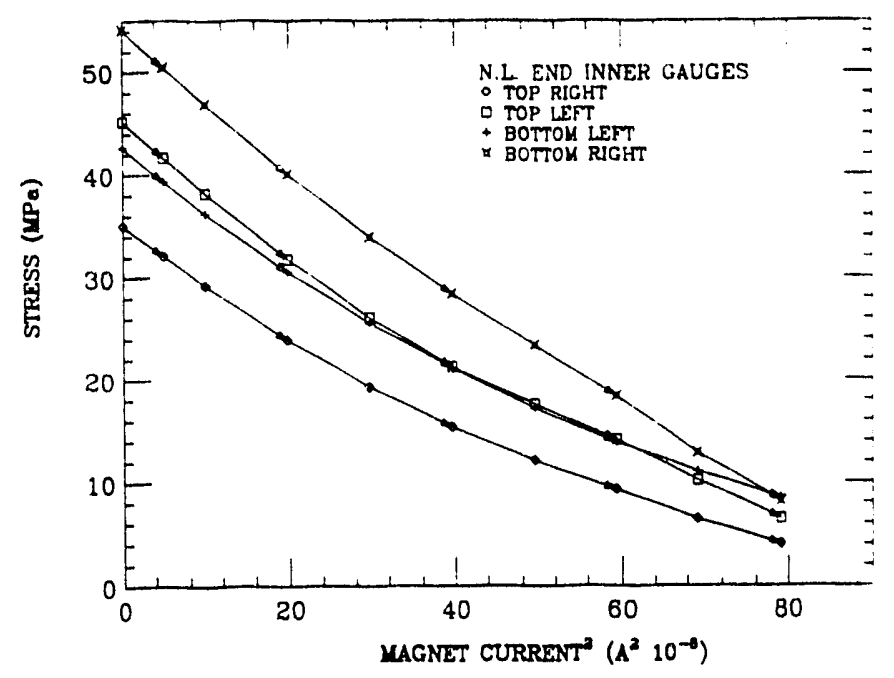

(a)

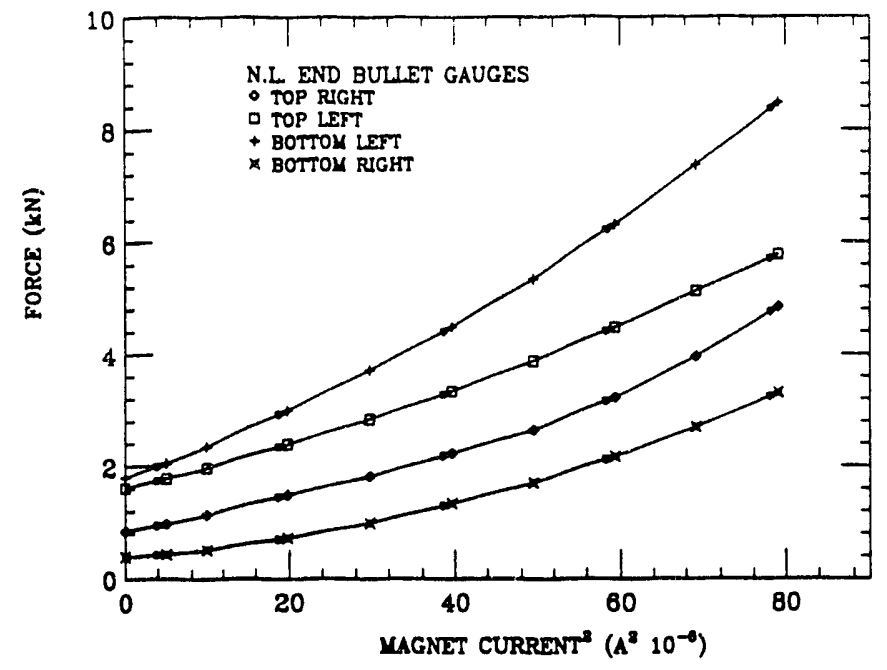

(b)

Figure 2. Azimuthal coil stress (a) and end-forces (b) as a function of $\mathrm{I}^{2}$ for the magnet DCA322 Data taken at $1.8 \mathrm{~K}$ during the strain gauge run to quench.

\section{ACKNOWLEDGMENTS}

We are grateful to the Fermilab and the SSC Laboratory design team and the Fermilab production staff for their excellent work during this project. We also wish to thank the staff of the Fermilab Magnet Test Facility for their dedication and support of the test program there.

\section{REFERENCES}

1. A. Devred, et al., "Review of SSC Dipole Magnet Mechanics and Quench Performance," Supercollider 4, J. Nonte ed., 1992, pp. 113-136..

2. J. Kuzminski, et al., "Quench Performance of 50-mm Aperture, 15-m-Long SSC Dipole Magnets Built at Fermilab", Proc. of the XV-th International Conference on High Energy Accelerators, Hamburg, 1992, Int. J. Mod. Phys. A (Proc. Suppl.) 2B (1993) pp. 588-591.

3. J. Strait, et al, "Mechanical Design of the 2D Cross-Section of the SSC Collider Dipole Magnets", Proceedings of the 1991 IEEE Particle Accelerator Conf.,1991, p 2127.

4. J. S. Brandt, et al., Coil End Design for the SSC Collider Dipole Magnet, ibid, p.2182.

5. C. L. Goodzeit, M. D. Anarella, and G. L. Genetis, "Measurement of Internal Forces in Superconducting Accelerator Magnets with Strain gauge Transducers", IEEE Trans. Mag. 25, No. 2, 1989, pp 14551458.

6. R. Sims, et al., "A Study of Variation in Cable Insulation Systems and their Effect on Creep", presented at the Fiftht International Industrial Symposium on the Supercollider, San Francisco, May, 1993. To be published in Supercollider 5. 

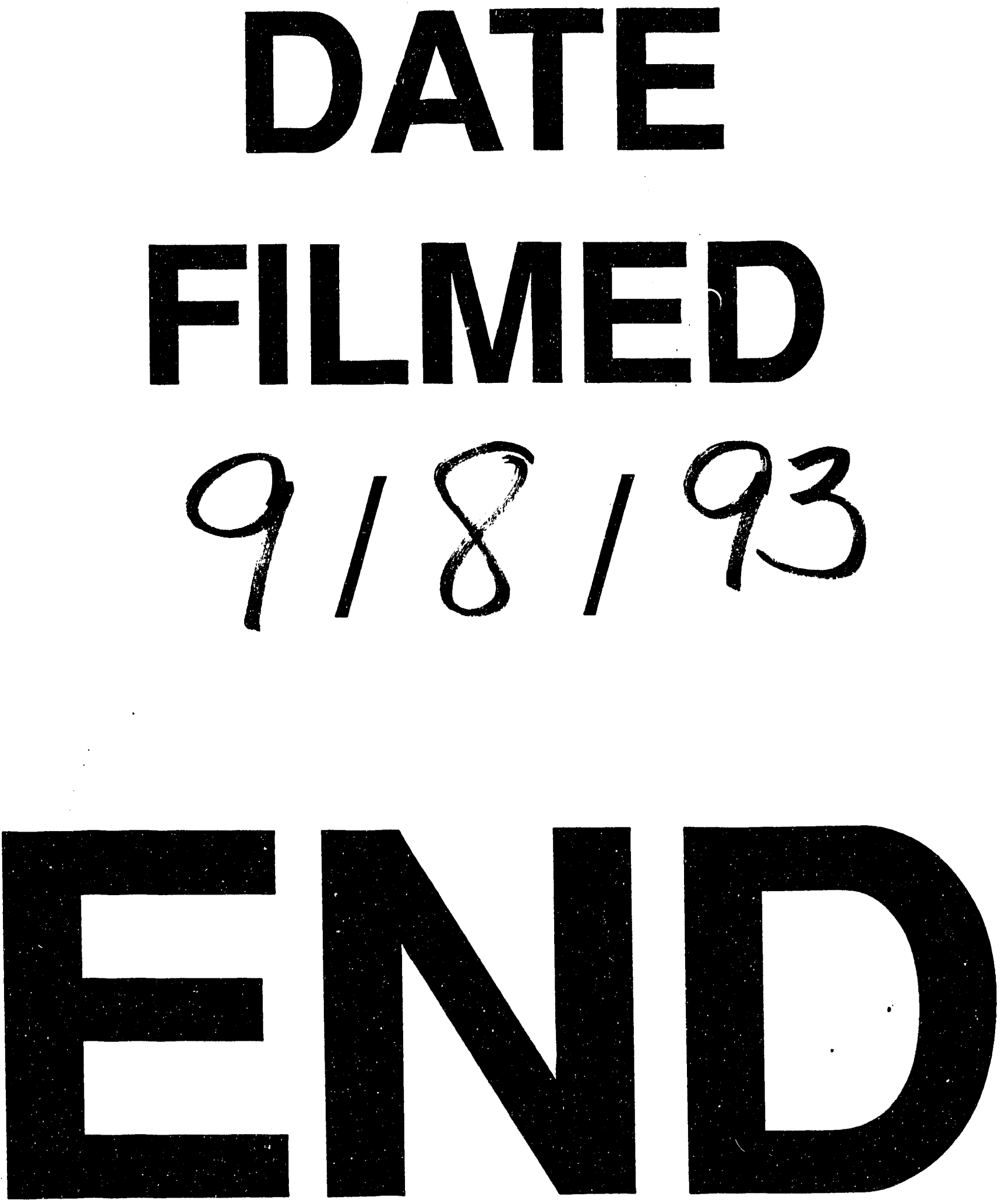
